\title{
The Value of a Policy-Responsive Research Funding Model: The Geohealth Laboratory Collaboration in New Zealand
}

\author{
Malcolm Campbell, Jesse Wiki, Lukas Marek, Matthew Hobbs, Matthew \\ Wilson and Simon Kingham
}

This chapter discusses the GeoHealth Laboratory (GHL) research model that is based on a relationship contract funding model between two parties, the University of Canterbury (UC) and the New Zealand Ministry of Health (MoH) around health geography, spatial epidemiology, and Geographical Information Systems (GIS). Further, the GHL seeks to produce high-quality research (i.e. journal articles) and policy-relevant outputs (e.g. in the form of plain English reports) in the fields of health and GIS. The chapter discusses the nature of the relationship and funding model, with examples of research from the annual research programme. We conclude by showing the importance of flexibility in research funding models, using emerging exemplars of research related to the COVID-19 response in New Zealand.

\subsection{What Is the GeoHealth Laboratory?}

The GeoHealth Laboratory (GHL) is a collective of researchers interested mainly in Quantitative Health and Medical Geography, based at the University of Canterbury (UC), New Zealand. The GHL began in 2005 as a strategic partnership between UC and the New Zealand Ministry of Health $(\mathrm{MoH})$ [1] that provides a resource that is unique in the Southern Hemisphere. The aim of the collaboration is to build a strategic partnership between the two parties around health geography, spatial epidemiology, and Geographical Information Systems (GIS). It seeks to produce high-quality research (i.e. journal articles) and policy-relevant outputs (e.g. in the form of plain English reports) in the fields of health and GIS. The GHL programme has published across a range of topics including: inequity [2], inequity of mortality [3, 4], oral health $[5,6]$, social connection [7], obesity $[8,9]$ and natural disasters and health $[10,11]$ to highlight a few key themes. Researchers from the GHL also have a longstanding interest in policy relevant or responsive research. This includes using spatial microsimulation, a modelling technique, to understand the impacts on government health policy $[12,13]$ as well as in a NZ context to understand the social and spatial patterns in obesity [14]. The GHL also aims to increase research capability through a program of research degree scholarships, primarily through the Masters of Spatial Analysis for Public Health $\left(\mathrm{MSAPH}^{1}\right)$ and

\footnotetext{
${ }^{1}$ https://www. canterbury.ac.nz/study/qualifications-and-courses/masters-degrees/master-of-spatialanalysis-for-public-health/
} 
teaching, for example, a course entitled 'Spatial Analytics for Health'. This has resulted in a series of skilled graduates who are now employed throughout New Zealand and overseas ${ }^{2}$.

\subsection{The Funding Model}

The nature of the relationship between $\mathrm{UC}$ and $\mathrm{MoH}$ means that the collaboration between the parties is funded ${ }^{3}$ in advance, much like a research programme with several project outlines included as indicative components of the overarching programme. Subsequently, the precise detail of the research and scholarship projects are negotiated and co-designed by both academic staff and $\mathrm{MoH}$ staff (who act as a project stakeholder). An important aspect of the GHL model is that the projects are subject to change if circumstances require. This ability to change the direction of a research project provides flexibility, meaning that as research priorities change, so too can the research projects and the precise topics investigated. Enabling changes to projects, without changes to the whole programme, reduces the bureaucratic overhead in contracting and bidding for individual research projects, focusing instead on rapid delivery of timely results directly to policymakers. Thus, the funder of the research benefits from the transfer of effort from managing and administration of the bureaucratic overhead (for both parties) to the delivery of research outputs. The nature of the high level of trust in our collaboration and the built-in flexibility of the contract is a stark contrast to conventional funding routes. UC contributes a proportion of the time of two Directors (note in New Zealand, $40 \%$ of an academic's usual role is related to research, $40 \%$ to teaching and $20 \%$ to administration) and hosts the laboratory space in which the GHL. A key strength of the GHL is the critical mass of academic expertise in GIS and health. Moreover, being located within the multi-disciplinary Geospatial Research Institute (GRI) provides an opportunity to develop geospatial research in aligned areas for which health is an important factor, such as in the area of hazards research. Having a critical mass of academics and researchers with similar interests means that there is the possibility of securing additional funding and resources beyond the principal funding streams that come from $\mathrm{MoH}$ and UC. Historically the GHL funded has included a range of sources such as the Health Research Council (HRC), NZ Transport Agency (NZTA), Foundation for Research Science and Technology (FRST), The Cooperative Research Centre - Spatial Information (CRCSI), and Ministry of Health's Environmental Health Indicators Programme.

\subsection{The Work Programme}

The original work programme for 2019/20 consisted of six projects that were co-designed with stakeholders on the following topics: transient populations, major trauma injuries, alcohol-related harm, mental health, maternity and disability. However, with the need to support the Ministry's response to COVID-19 the work programme was reviewed to enable rapid delivery of outputs relating to data supply and the visualisation of COVID-19 cases (see Figure 41.1) as well as the identification of vulnerable populations based on demographic factors. Additionally, a project on population mobility was designed that utilises nationwide mobile phone data to analyse mobility patterns before, during and after national lockdown measures were implemented. This provides important information about the extent of population compliance to lockdown measures and how this varies during different periods of pandemic policy and alert levels ${ }^{4}$, particularly by geographic area and socioeconomic status. The project also aims to allow for a better understanding of mobility patterns between places using a combination of traditional data sources such as Census travel data

\footnotetext{
${ }^{2}$ https://www. canterbury.ac.nz/science/research/geohealth/ (See "Former Postgraduate Students").

${ }^{3}$ The GeoHealth Laboratory is funded by the New Zealand Ministry of Health until June 2021.

${ }^{4}$ https://covid19.govt.nz/assets/resources/tables/COVID-19-alert-levels-summary.pdf
} 
and the aforementioned mobile phone data. The results of the project are still emerging, however, we have reported the changing spatial patterns in mobility across NZ as well as the social and spatial differences that relate to the socio-economic position of neighbourhoods across NZ The ability to be flexible with projects provided significant advantages, ensuring the GHL work programme met the immediate and changing priorities of $\mathrm{MoH}$.

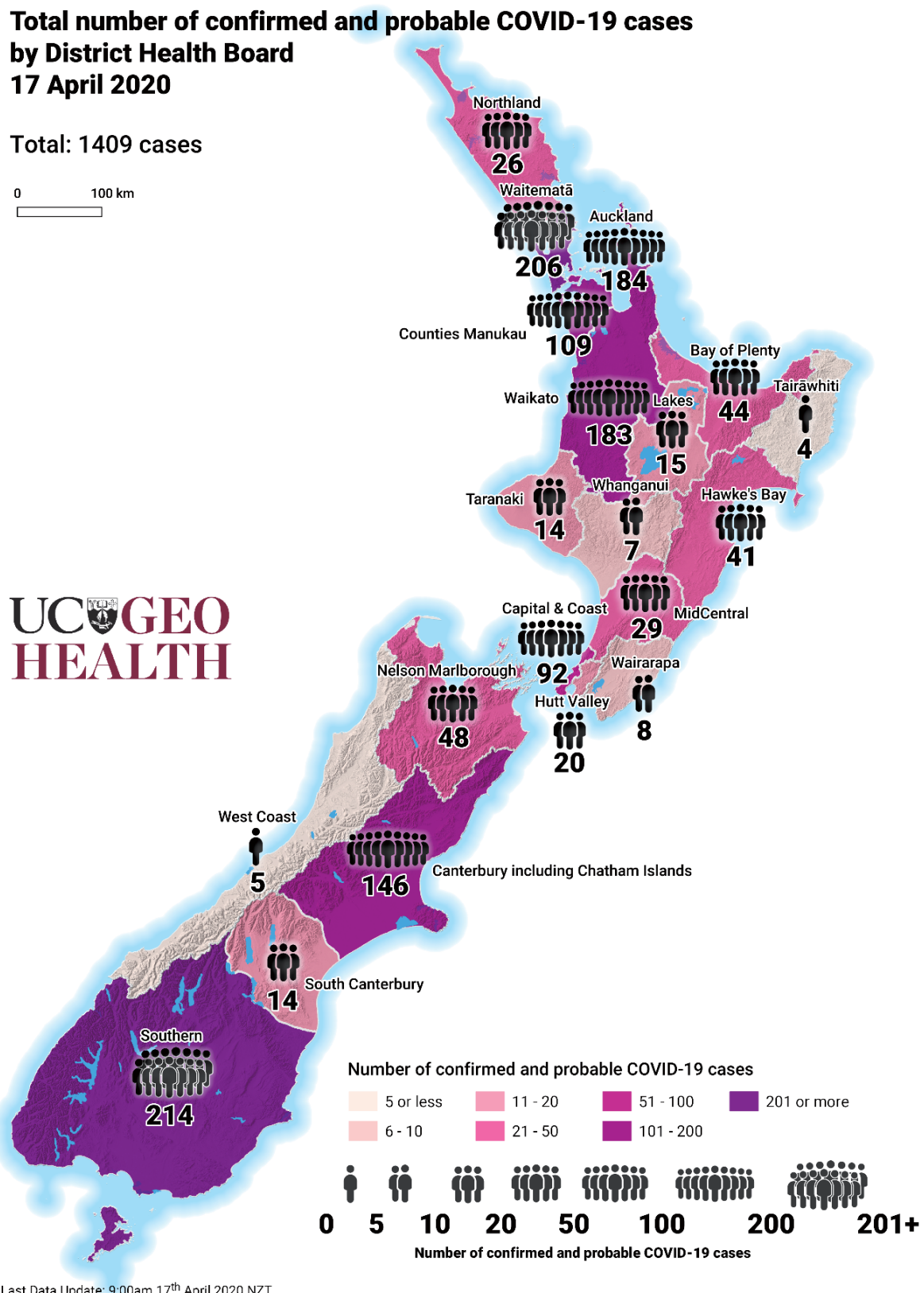

FIGURE 41.1

Spatial distribution of COVID-19 cases in New Zealand. 17 April 2020. 


\subsection{Conclusion}

The key lessons learnt, from our observation and experience is that by utilising a relationship contract, rather than a project-based contract has particular advantages in times of significant disruption, especially when flexibility and responsiveness are required at short notice. Specifically, the ability to change projects which are valuable in the long term, but have no immediate urgency when compared to the rapid response needed for the COVID-19 pandemic. A project-based funding model is not as resilient or flexible to external events that require, or indeed that would benefit from a change in project scope. The GHL model mitigates this risk and allows the opportunity for research capacity to be redirected. Additionally, the GHL model is also more robust even when anticipated changes create a need for a change in projects and priorities. We would further argue that thinking about a relationship contract approach is particularly salient for those who contract and fund research due to the points discussed above. In a time of a pandemic, particularly in New Zealand, we have demonstrated that having skilled researchers and a flexible funding model produced an important contribution to national efforts to better understand and tackle COVID-19, thereby enhancing community resilience.

\section{References}

[1] Christopher Bowie, Paul Beere, Edward Griffin, Malcolm Campbell, and Simon Kingham. Variation in health and social equity in the spaces where we live: A review of previous literature from the geohealth laboratory. New Zealand Sociology, 28(3):164-191, 2013.

[2] Matthew Hobbs, Annabel Ahuriri-Driscoll, Lukas Marek, Malcolm Campbell, Melanie Tomintz, and Simon Kingham. Reducing health inequity for Māori people in New Zealand. The Lancet, 394(10209):1613-1614, 2019 .

[3] Malcolm Campbell, Philippe Apparicio, and Peter Day. Geographic analysis of infant mortality in New Zealand, 1995-2008: an ethnicity perspective. Australian and New Zealand Journal of Public Health, 38(3): 221-226, 2014. doi: 10.1111/1753-6405.12222. URL https://onlinelibrary.wiley.com/doi/abs/10.1111/17536405.12222

[4] M. Campbell, C. Bowie, S. Kingham, and J.P. McCarthy. Painting a picture of trans-tasman mortality. Public Health, 129(4):396-402, 2015. ISSN 0033-3506. doi: https://doi.org/10.1016/j.puhe.2015.01.015.

[5] Matthew Hobbs, Lukas Marek, Riana Clarke, John McCarthy, Melanie Tomintz, Alicia Wade, Malcolm Campbell, and Simon Kingham. Investigating the prevalence of non-fluoride toothpaste use in adults and children using nationally representative data from New Zealand: a cross-sectional study. British Dental Journal, 228(4):269-276, 2020. ISSN 1476-5373. doi: 10.1038/s41415-020-1304-5. URL https: //doi.org/10.1038/s41415-020-1304-5.

[6] Matthew Hobbs, Alicia Wade, Peter Jones, Lukas Marek, Melanie Tomintz, Kanchan Sharma, John McCarthy, Barry Mattingley, Malcolm Campbell, and Simon Kingham. Area-level deprivation, childhood dental ambulatory sensitive hospitalizations and community water fluoridation: evidence from New Zealand. International Journal of Epidemiology, 49(3):908-916, 04 2020. ISSN 0300-5771. doi: 10.1093/ije/dyaa043. URL https://doi.org/10.1093/ije/dyaa043.

[7] Clémence Vannier, Malcolm Campbell, and Simon Kingham. Pathways to urban health and well-being: measuring and modelling of community services' in a medium size city. Geospatial Health, 15(1), June 2020. ISSN 1827-1987. doi: 10.4081/gh.2020.808. URL https://doi.org/10.4081/gh.2020.808.

[8] Matthew Hobbs, Melanie Tomintz, John McCarthy, Lukas Marek, Clémence Vannier, Malcolm Campbell, and Simon Kingham. Obesity risk in women of childbearing age in New Zealand: a nationally representative cross-sectional study. International Journal of Public Health, 64(4):625-635, May 2019. ISSN 1661-8556. doi: 10.1007/s00038-019-01239-8. URL https://doi.org/10.1007/s00038-019-01239-8.

[9] Jesse Wiki, Simon Kingham, and Malcolm Campbell. Accessibility to food retailers and socio-economic deprivation in urban New Zealand. New Zealand Geographer, 75(1):3-11, 2019. doi: 10.1111/nzg.12201. URL https://onlinelibrary.wiley.com/doi/abs/10.1111/nzg. 12201.

[10] Daniel Hogg, Simon Kingham, Thomas M. Wilson, and Michael Ardagh. The effects of relocation and level of affectedness on mood and anxiety symptom treatments after the 2011 Christchurch earthquake. Social Science ES Medicine, 152:18-26, 2016. ISSN 0277-9536. doi: https://doi.org/10.1016/j.socscimed.2016.01.025. URL http://www.sciencedirect.com/science/article/pii/S0277953616300259. 
[11] Daniel Hogg, Simon Kingham, Thomas M. Wilson, and Michael Ardagh. Spatio-temporal variation of mood and anxiety symptom treatments in christchurch in the context of the 2010/11 canterbury earthquake sequence. Spatial and Spatio-temporal Epidemiology, 19:91-102, 2016. ISSN 1877-5845. doi: https://doi. org/10.1016/j.sste.2016.08.001. URL http://www.sciencedirect.com/science/article/pii/S1877584515300046.

[12] Malcolm Campbell and Dimitris Ballas. Simalba: A spatial microsimulation approach to the analysis of health inequalities. Frontiers in Public Health, 4:230, 2016. ISSN 2296-2565. doi: 10.3389/fpubh.2016.00230. URL https://www.frontiersin.org/article/10.3389/fpubh.2016.00230.

[13] Malcolm H Campbell. Exploring the social and spatial inequalities of ill-health in Scotland: A spatial microsimulation approach. PhD thesis, University of Sheffield, October 2011. URL http://etheses. whiterose.ac.uk/1942/.

[14] Alison F. Watkins. Exploring the social and spatial context of adult obesity in Aotearoa New Zealand : a spatial microsimulation approach. PhD thesis, University of Canterbury, 2017. URL https://ir.canterbury . ac.nz/handle/10092/15643. 
$\Longrightarrow$ Taylor \& Francis Taylor \& Francis Group

http://taylorandfrancis.com 